\title{
SNaP 2: the Evolution of a Board Game for Smart Nature Environments
}

Rosella Gennari

Free University of

Bozen-Bolzano

Piazza Domenicani 3, Bolzano

gennari@inf.unibz.it

Maristella Matera

Politecnico di Milano

Via Ponzio, 34/5, 20133, Milano

maristella.matera@polimi.it

Alessandra Melonio

Free University of

Bozen-Bolzano

Piazza Domenicani 3, Bolzano

alessandra.melonio@unibz.it

Eftychia Roumelioti

Free University of

Bozen-Bolzano

Piazza Domenicani 3, Bolzano

eftychia.roumelioti@unibz.it

Permission to make digital or hard copies of part or all of this work for personal or classroom use is granted without fee provided that copies are not made or distributed for profit or commercial advantage and that copies bear this notice and the full citation on the first page. Copyrights for third-party components of this work must be honored. For all other uses, contact the owner/author(s).

Copyright held by the owner/author(s).

CHI'20,., April 25-30, 2020, Honolulu, HI, USA

ACM 978-1-4503-6819-3/20/04.

https://doi.org/10.1145/3334480.XXXXXXX

\begin{abstract}
$\mathrm{SNaP}$ is a collaborative board game for children. In the game, children become Designers and the protagonists of the ideation of smart nature ecosystems, reflecting on them. This paper presents the evolution of the game and its usage in a recent workshop with 11-years old children.
\end{abstract}

\section{Author Keywords}

board game; child-centred computing; smart objects

\section{CCS Concepts}

-Human-centered computing $\rightarrow$ Empirical studies in interaction design:

\section{Introduction and Related Work}

Children's roles in the design of technology have been widely investigated, e.g., [5]. Recently, the role of protagonist has emerged as relevant and critical, e.g., [9]. As protagonists, children should be empowered to guide the design process: to this end, they should be engaged in the ideation of technology for an environment meaningful for them, and in the reflection on its usage [8]. This is the perspective taken in this paper, in which children become protagonists of the ideation of smart objects for a nature environment, reflecting on the usage of technology for it.

Cards have been used for ideating smart objects for smart 
cities, albeit mainly with adults. Examples are the loTT Card Set [1], the loT Design Deck [3] and the Tiles Cards [10]. This paper also uses cards for ideating smart objects but for nature environments, and by embedding them in a board game, which structures the ideation and reflection parts of the design process for 9-14 years old children.

This paper presents the evolution of the board game, then the novel design of the board game, how this was used in a novel ideation workshop and its results.

\section{The SNaP Game Evolution}

The Smart Nature Protagonists (SNaP) game is a collaborative board game for 9-14 years old children, with ideas taken from cards for loT outlined above, and traditional board games [11]. The game is played by a group of 2 to 4 children, who act as Designers, plus an expert of smart objects, who plays the role of Mayor. The goal and briefing statement of the game is as follows: the Mayor wants to organise a festival in the town's park, and needs Designers' help to enhance the park with smart objects for preteens and teens. The game terminates when the winningcondition is satisfied: each player has created at least one smart object for the park.

Three groups, each of 4 children, used the first version of SNaP, i.e., SNaP 1, in three workshops, reported in two different papers [6, 7]. Each player ideated at least one smart object. According to the gathered data, all players were engaged and learned how to ideate smart objects. Ideas for improvement to the gameplay also emerged, and hence SNaP 1 evolved into SNaP 2. After three weeks from playing with $\mathrm{SNaP} 1$, a group played again with $\mathrm{SNaP} 2$ in a novel workshop. SNaP 2 and this workshop are reported below for the first time.

\section{The SNaP Game Design}

The SNaP 2 board game has 3 main elements: decks of Cards, the Scaffolding Map, and the Game Board itself.

Cards

In $\mathrm{SNaP} 1$, the cards were composed of four categories: (1) 18 Environment Cards, for objects of a park or an outdoors nature environment; (2) 25 Input and Output Cards, for input devices (e.g., a button) and output devices (e.g., an LED) for interacting with Environment Cards; (3) 4 Mission Cards, related to the game goal above. After the workshops with children with SNaP 1, extra cards were added to the Input and Output Cards, besides for web services (e.g., weather forecast, news). New Mission Cards were also added, (e.g., facilitate healthy activities and/or promote community wellness), so as to offer a wider variety of choices. Role Cards are new features of SNaP 2. These were added to enforce inter-dependence and hence strengthen the collaboration among players: they assign specific roles and tasks to each player regarding ideas of smart objects. These cards adopts and adapts roles from cooperative learning [2], such as: (1) the Enrichment checker checks whether players can exploit unused cards for their ideas; (2) the Fun keeper checks if everybody's idea are fun and interesting; (3) the Consistency checker ensures that players' cards are used consistently; (4) the Time regulator can ask for an extra discussion round.

\section{An Interactive Scaffolding Map}

The Scaffolding Map (see Figure 1) serves to immerse players in the game, and to train players by means of examples of smart objects for nature ecosystems. The first version of the map was not interactive and it failed to offer clear examples to children. In the new Scaffolding Map (see Figure 1), Environment Cards (e.g., a flower) hide tags linking to video examples; these show smart objects (e.g., an interactive 
flower that "talks" and lights up when someone approaches it). Players are challenged to play and guess what Input and Output Cards can be used for making the smart objects.

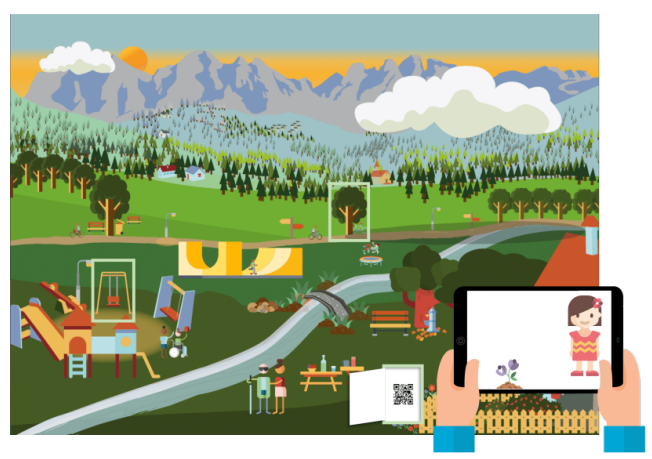

Figure 1: The scaffolding map

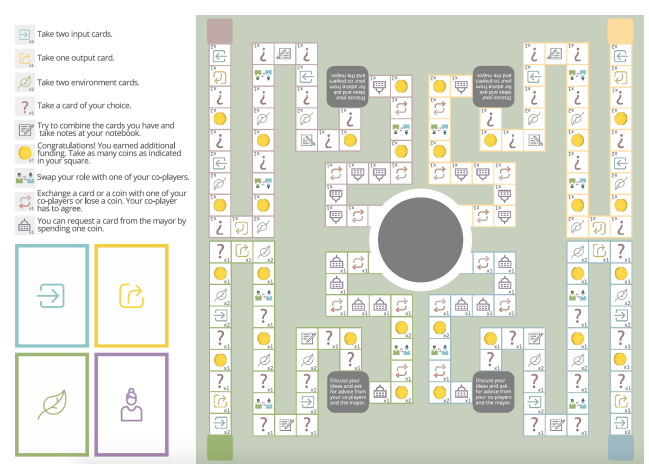

Figure 2: The Game Board

The Game Board and Gameplay

The Game Board of SNaP 2 is in Figure 2. For the setup of the game, the Mayor keeps coins and a copy of the cards described above. The cards are placed shuffled and faced down on the Game Board. At the beginning of the gameplay, each player takes a note sheet and a token. Players can either choose a specific mission from the Mission Cards to undertake in advance, or they can decide about it later, during the gameplay. Moreover, in the Game Board of SNaP 2, Role Cards are randomly selected at the beginning of the gameplay by each player.

Each player places his/her token at a different coloured square (see Figure 2) and tries to reach the central circle of the Game Board by throwing the dice and moving the token accordingly. Depending on the reached square, the player may be entitled to get one or more cards from the stacks of cards, get coins, try to combine the cards and take notes, exchange or buy a card. When the grey squares are reached, the players should have a discussion round to reflect on their cards and share their ideas in turns with the other players and the Mayor.

\section{Workshop with SNaP 2}

Questions, Participants and Workshop Format

With SNaP 2, we organised a workshop with the same group of 11-year old children who had participated in one of the workshops with SNaP 1. The purpose of the workshop was to assess SNaP 2 with children, and specifically to explore the following questions: (Q1) what ideas result from the gameplay, indicating whether the game enables children to ideate; (Q2) what interactions would occur among players, indicating whether the game fosters shared reflections; (Q3) how children would experience the game, indicating what can be improved.

The four kids, playing as Designers, were 2 females and 2 males; the same two $\mathrm{HCl}$ experts of the previous workshops also participated, one as Mayor and the other as observer. Kids participated on a voluntary basis, and their 
participation was authorised by their parents through a consent form. The workshop lasted about 2 hours, including the time for the introductory part and for the completion of a post-workshop questionnaire. Since the participants had already played with $\mathrm{SNaP} 1$, the workshop started with the scaffolding map. Only the new elements of the game were explained by the Mayor. Thus, the children were given the necessary materials to start the SNaP 2 gameplay.

\section{Data Collection}

Data concerning the workshops were related to children's ideas, interactions among them and their experience of the gameplay. Qualitative data were collected via indirect observations (videos, photos) and direct observations with interviews; the two design experts collected their observations independently and then compared their notes, resolving doubts through discussion, or by referring back to videos or photos. At the end of the gameplay, children filled in an experience questionnaire, with 16 questions concerning the new elements of the game and in general the gameplay, with a Liker-scale. Two open-ended questions also probed children about what they liked or would change.

Results and Reflections

Q1: Ideas.

The emerged ideas are reported in Table 1. In relation to the selected missions, the participants described the interaction of Input and Output Cards with Environment Cards according to the cards they gathered during the gameplay. In comparison with the previous workshop with $\mathrm{SNaP} 1$, the new ideas featured a higher complexity, in terms of the adopted cards and their combination. All participants used a higher number of cards, on average 6 cards $(\mathrm{min}=6$,

$\max =7$ ) versus 4 cards for the first workshop. The average percentage of unused cards was also lower: $18.65 \%$ for this second workshop versus $26.58 \%$ in the first one.
Such differences might be due to different factors, including the experience gained by the participants, being this a second game session. It is important to note, however, that the higher number of squares in the new version of the Game Board enabled participants to gain more cards, and that the digital examples in the interactive Scaffolding Map showed concrete examples of Input and Output Cards, and how to compose them with Environment Cards.

\section{Q2: Interactions.}

The interaction among the players also improved. Thanks to the Role Cards, everybody wanted to follow and understand what the others were doing. An interesting side effect of Role Cards is that, even if only one participant was in charge of checking the richness of the ideas, during the discussions every participant tried to enrich the others' ideas by suggesting additional features that could be introduced thanks to the collected cards.

In the previous workshop, nobody wanted to exchange cards with the other players. For tackling this situation, $\mathrm{SNaP} 2$ offered the possibility to gain more cards and a penalty in case of missing exchanges. However, it was not necessary to apply any penalty: in SNaP 2, participants spontaneously tried to exchange cards and share reflec-

tions. In fact, in every card exchange, the player promoting the exchange suggested the others how they could exploit the cards he or she was willing to exchange. From the players' perspective, this was a way for convincing the others to accept the exchange. From the gameplay perspective, this mechanism further augmented opportunities for sharing reflections on smart objects. The final ideas were rich not only because of the creativity of the single player, but also because of the reflection stimuli $s /$ he received from peers. 
Table 1: Ideas generated during the workshop with $\mathrm{SNaP} 2$; used cards are in capital

\begin{tabular}{|l|l|}
\hline Chosen Mission & Interactive objects \\
\hline $\begin{array}{l}\text { Provide an attractive } \\
\text { environment for the visi- } \\
\text { tors to spend more time } \\
\text { outdoor }\end{array}$ & $\begin{array}{l}\text { (1) a BUTTON can be mounted on a STREET SIGN; when it is pressed, a DISPLAY shows } \\
\text { images of the places that can be reached following the direction pointed by the sign; (2) a BUT- } \\
\text { TON can be attached on a BICYCLE fixed in a point of the park; when the button is pressed, a } \\
\text { DISPLAY mounted on the handlebars simulates a 3D experience, for example going on roller } \\
\text { coaster, also thanks to VIBRATIONS. }\end{array}$ \\
\hline $\begin{array}{l}\text { Provide a safe and com- } \\
\text { fortable environment }\end{array}$ & $\begin{array}{l}\text { To augment a TREE with a SPEED sensor, thus if a person runs fast a SOUND is emitted or a } \\
\text { voice tells the person that s/he is proceeding too fast; }\end{array}$ \\
\hline $\begin{array}{l}\text { Enhance the interaction } \\
\text { among people }\end{array}$ & $\begin{array}{l}\text { A STREET SIGN is augmented with a MOTION sensor. If a person gets close to the street } \\
\text { sign, the motion sensor reveals it and the street sign rotates (MOVE) towards a person that sits } \\
\text { on a BENCH nearby, as detected by the DISTANCE sensor. }\end{array}$ \\
\hline $\begin{array}{l}\text { Help visitors learn of } \\
\text { nature elements }\end{array}$ & $\begin{array}{l}\text { To enrich FLOWERS and BRIDGES with a MOTION sensor. When somebody passes close to } \\
\text { a flower or to a bridge, a light is switched on (LIGHT UP) and a voice (SOUND) tells the story } \\
\text { of the river passing under the bridge, or explains the characteristics of the flower species. A } \\
\text { DISPLAY, close to the flower or bridge, shows related images. }\end{array}$ \\
\hline $\begin{array}{l}\text { Facilitate healthy ac- } \\
\text { tivities and/or promote } \\
\text { community wellness }\end{array}$ & $\begin{array}{l}\text { If a person wants to have a healthy activity, s/he can touch a BUTTON, mounted on STAIRS or } \\
\text { on a BICYCLE. A recorded voice (SOUND) explains exercises that can be done with the stairs } \\
\text { or with the bicycle. The recorded voice also says to wear a strap around the wrist to sense the } \\
\text { HEART RATE. If the rate is too high, then the voice orders the person to stop and to take a rest } \\
\text { on the BENCH and drink water from the DRINKING FOUNTAIN. }\end{array}$ \\
\hline
\end{tabular}

Q3: Experience of the Game.

The data gathered through the final questionnaire highlighted that the players loved very much most of the newly introduced elements, namely the new interactive map $(\bar{x}=$ 9.25 , with $0=$ "did not like" and $10=$ "loved it"), the videos to explain how to augment nature elements $(\bar{x}=8.5)$, and the introduction of roles $(\bar{x}=8.25)$.

The elements they preferred least were the new missions $(\bar{x}=7.25)$. According to qualitative data, the higher number of missions to choose from introduced some difficulties for some participants. Interviewed, they felt like some new mis- sions were not easy to solve as they were too vague and perhaps far from their park experience.

Moreover children did not like very much their note sheets $(\bar{x}=6.5)$, and indeed during the workshop they had a low attitude to use it for taking notes and organising cards. One possible motivation might be that the game requires them to perform other, more engaging actions (i.e., throwing the dice and moving the token, selecting cards, thinking about how to assemble solutions), thus they do not have time to write down notes, or at least they do not perceive this as an important activity. It was also observed that children pre- 
ferred having all cards visible on the table, to stacking them on the note sheet.

Their perception of the game was positive. On average, the players found that the game was moderately complex $(\bar{x}=6$, with $0=$ "very easy", $10=$ "very complex") and expressed the same for the game instructions and rules $(\bar{x}=5.75)$. However, the question about the uniqueness of the game in comparison with other games they knew got an average score of 8.75 ( 0 = "not much different", 10 = "very different"), and the score for their interest in the game was 9.5 ( 0 = "it was boring", 10 = "loved it"). The average score for the question "How often will you play this game?" was also high ( $\bar{x}=9$, with $0=$ "never again", $10=$ "a lot").

An interesting result was that players themselves found that the game gave them many opportunities to interact. The average score for the question "How much did the gameplay cause you to interact with other players" was 9 ( $0=$ "never", 10 = "all the time"). Another question asking players if the game results depended on luck or skill got an average score of 5.75 ( 0 = "only luck"; 10 = "only skill"). This result seems to reflect that the players felt that their skills, thus their commitment in generating the ideas, contribute to the quality of the final results.

The answers to the open questions seem to confirm these results. To all players, the new version of the game seems much better than the previous; they liked the new elements very much. Also, they did not point out any specific idea to improve the game ("No, I don't have any idea because the game is already fantastic as is!"). Two players suggested increasing the duration of the game path even more, which was a request already emerged in the first workshop.

Such results give, overall, a positive perception of the game experience, and indications for future work, discussed in the following.

\section{Conclusions and Future Work}

This paper reports on the design of SNaP 2, the second version of a collaborative board game for 11-14 years old children. The game aims at making children protagonists in the ideation and reflections concerning smart objects for nature environments. To this end, SNaP 2 tangibly structures children's ideas and promotes shared reflections.

SNaP 2 emerged from usages in past workshops. This paper reports on its main design features and on a novel workshop with four 11-year old children. The workshop gave a rich set of qualitative and quantitative data which indicate that the game, in its new version, enables children to become protagonists: it elicited children's ideas concerning smart objects for nature environments, encouraged interactions for reflecting on ideas, and promoted an overall quality experience. Indications for future work also emerge from the workshop. Only the main ones are discussed in the following due to space limits.

Future work will be devoted to improve the game experience, in line with the results of the questionnaire, with further instruments to assess the game experience, e.g., [4]. For instance, a new hybrid game version is under development, for keeping track of cards and ideas exchanged during the game, without note sheets which children did not enjoy. Minimising randomness in the choice of Input and Output cards will also be relevant for enabling players to ideate what they like best.

Generalising the results of the present work will also be addressed by future work. Moreover, in line with past research in the field, e.g.., $[9,8]$, it will also be important to engage children in the follow-up steps of the design process: in the making of some of their own ideas. 


\section{REFERENCES}

1. Leonardo Angelini, Elena Mugellini, Nadine Couture, and Omar Abou Khaled. 2018. Designing the Interaction with the Internet of Tangible Things: A Card Set. In Proceedings of the Twelfth International Conference on Tangible, Embedded, and Embodied Interaction (TEI '18). ACM, New York, NY, USA, 299-306. DOI :

http://dx.doi.org/10.1145/3173225.3173288

2. Buckley Barnes and Gail O'Farrell. 1990. Cooperative Learning Strategies. Social Studies and the Young Learner 2, 3 (1990).

3. Massimiliano Dibitonto, Federica Tazzi, Katarzyna Leszczynska, and Carlo M. Medaglia. 2018. The loT Design Deck: A Tool for the Co-design of Connected Products. In Advances in Usability and User Experience, Tareq Ahram and Christianne Falcão (Eds.). Springer International Publishing, Cham, 217-227.

4. G. Dodero, R. Gennari, A. Melonio, and S. Torello. 2015. "There is no rose without a thorn": An assessment of a game design experience for children. ACM International Conference Proceeding Series 28 (2015), 10-17. DOI : http://dx.doi.org/10.1145/2808435.2808436

5. Allison Druin. 2002. The role of children in the design of new technology. Behaviour and Information Technology 21 (2002), 1-25.

6. Rosella Gennari, Maristella Matera, Alessandra Melonio, and Eftychia Roumelioti. 2019a. A Board Game and a Workshop for Co-Creating Smart Nature Ecosystems. In Proceedings of 9th International Conference in Methodologies and Intelligent Systems for Technology Enhanced Learning (mis4TEL 2019). Springer. DOI :

http://dx.doi.org/10.1007/978-3-030-23990-9_17

7. Rosella Gennari, Maristella Matera, Alessandra Melonio, and Eftychia Roumelioti. 2019b. A Board-Game for Co-Designing Smart Nature Environments in Workshops with Children. In Proceedings of the 7th International Symposium on End-User Development (is-EUD 2019). Springer. DOI : http: //dx.doi.org/10.1007/978-3-030-24781-2_9

8. Netta livari and Marianne Kinnula. 2018. Empowering Children Through Design and Making: Towards Protagonist Role Adoption. In Proceedings of the 15th Participatory Design Conference: Full Papers-Volume 1 (PDC '18). ACM, New York, NY, USA, Article 16, 12 pages. DOI :

http://dx.doi.org/10.1145/3210586.3210600

9. Ole Sejer Iversen, Rachel Charlotte Smith, and Christian Dindler. 2017. Child As Protagonist:

Expanding the Role of Children in Participatory Design. In Proceedings of the 2017 Conference on Interaction Design and Children (IDC '17). ACM, New York, NY, USA, 27-37. DOI :

http://dx.doi.org/10.1145/3078072.3079725

10. Simone Mora, Francesco Gianni, and Monica Divitini. 2017. Tiles: A Card-based Ideation Toolkit for the Internet of Things. In Proceedings of the 2017 Conference on Designing Interactive Systems (DIS '17). ACM, New York, NY, USA, 587-598. DOI : http://dx.doi.org/10.1145/3064663.3064699

11. Katie Salen and Eric Zimmerman. 2003. Rules of Play: Game Design Fundamentals. The MIT Press. 